\title{
TRAFFIC POLLUTION IN URBAN JORDAN
}

\author{
Ali F. Al-Shawabkeh ${ }^{1}$ and Mohd R. Suliman \\ Faculty of Engineering Technology, Al-Balqa' Applied University, Amman, Jordan \\ ${ }^{1}$ Corresponding Author: drshawabkeh@fet.edu.jo
}

(Received August 31, 2005 Accepted September 20, 2005)

Gasoline and diesel are the only vehicular fuel used in Jordan. Gasoline operates about $60 \%$ of the total vehicles, light-to-medium diesel trucks are about $15 \%$ and heavy vehicles including transit buses total $25 \%$. The local gasoline is produced by the only oil refinery in Jordan and is located in Al-Zarka area. This gasoline is leaded gas contains $1 \%$ Lead. The production of unleaded gasoline has just begun in Jordan where very few gas stations sell the product to less than $1 \%$ of total vehicles. Diesel fuel produced at the Jordan Refinery contains up to $1.5 \%$ sulfur.

Field study on vehicle emission and factors affecting the type and quantity of emissions is conducted. Traffic congestion, type and age of vehicles, and topography are considered. A sample of 724 vehicles has been tested in a joint project carried out by The Ministry of Environment (MOE) and The Public Security Directorate (PSD). The data obtained from this project was studied and analyzed by the two researchers at the Faculty of Engineering Technology/Al-Balqa' Applied University. Three hundred and eighty-five vehicles using leaded gasoline were tested. Thirty-six of which ran on unleaded fuel. The rest of the sample vehicles used diesel fuel. The ratio of vehicles using gasoline to diesel fuel, approximately, represents the total number of vehicles using gasoline and diesel fuel on Jordanian roads. Other data on vehicle maintenance was collected at a gas station in the suburbs of the capital. It is found that $60 \%$ of the tested gasoline vehicles exceeded the allowable Jordanian standards of one or more pollutants. On the other hand, more than $57 \%$ of the tested diesel vehicles were in violation of the emission standard in the Kingdom. These local standards tolerate more limits and are less restricted than US. EPA and European Standards. The analysis of results showed different degrees of violation depending on the age group of the vehicles. A higher rate of violation (64\%) was detected in the subgroup representing the age from 10 to 15 years. The age group of five years or less showed the highest rate of success.

Records of maintenance were collected for some vehicles at a local service station. A basic questionnaire of 350 car owners was made.

High rate of vehicular emission is due in parts to old vehicle and lack of maintenance. More than $53 \%$ of tested vehicles are older than 10 years of age. The study stresses on the health risks associated with each pollutant. Further more, it suggests alternative solution to mitigate the pollution problem.

KEYWORDS: Traffic pollution, tailpipe emission, vehicular emission. 


\section{INTRODUCTION}

\section{BACKGROUND}

The problem of air pollution is not new. Naturally produced pollutants have been release to the earth's atmosphere since the creation of the planet. These pollutants were released and stabilized by natural processes. This course continued and nature healed itself until man has started burning fossil fuel and coal over the past several centuries. Also, the pollution problem from traffic arises due to the increase of population.

There are over half a million of cars in Jordan. According to a local study, each car is driven an average of 15,000 kilometers annually. This means that Jordanians drive more than eight billion kilometers every year. The transportation sector in Jordan is the dominant energy consumer (about 50\% of the total energy package, year 2000). More than $80 \%$ of the total vehicles in the Kingdom are registered in the Amman/AlZarka Metropolitan areas, where more than three quarters of the population live. The mountainous topography and calm wind in certain seasons result in a high concentration of vehicle emissions in the two cities. Moreover, this area is the home of more than $85 \%$ of the total industries in the country. This makes pollution issues of more concern to citizens.

More recently, connections between air pollution and respiratory ailments, cancer, and heart disease have been demonstrated on the local and global scale. Detrimental environmental effects on the global scale have been investigated. Several localized and highly contaminate pollution episodes have resulted in documented deaths and then, highlighted the severity of the problem. This mandates the formulation of specialized agencies and authorized bodies to regulate and control the problem. International organizations such as Environmental Protection Agency (EPA) and World Health Organization (WHO) were established to set and regulate standards and limits of pollutants and other hazardous substances.

There are three main sources of pollution related to traffic and traffic operation. Traffic pollution starts from mining to extract metals to be used for vehicle manufacturing and continues even after the disposal of the vehicle in the scrap yard. Roadway acquisition and construction, pavements, service stations, noise, and rubber tires are some the many pollution sources related to traffic. The scope of this study, however, is concerned with elements of pollution associated with emissions resulting from operating the vehicle on roadways. This emission may take place while pumping fuel, cranking, and running the vehicle. Crankcase emissions are defined as the airborne substances emitted to the atmosphere from the portion of the engine crankcase ventilation or lubrication system. Unburned hydrocarbons (HC), carbon monoxide $(\mathrm{CO})$, carbon dioxide $\left(\mathrm{CO}_{2}\right)$, and lubricating oils are the main pollutants emitted from the crankcase. $\mathrm{HC}$ amounts to $80 \%$ of crankcase emissions, while other pollutants account for the remainder [2]. Also, evaporation is mainly HC emitted from fuel tanks and service stations. Exhaust emission which is the main source of vehicular pollution including $\mathrm{CO}, \mathrm{CO}_{2}$, nitrogen oxides $\left(\mathrm{NO}_{\mathrm{x}}\right)$, sulfur dioxide $\left(\mathrm{SO}_{2}\right)$, and suspended particles. Airborne lead released from vehicle exhaust causes liver, kidney, and brain damage in humans. In addition, it is responsible for damaging agricultural crops. 


\section{OBJECTIVES}

The main objective of this research paper is to assess of the magnitude of vehicular emission in urban Jordan and its effect on citizens. The main exhaust pollutants and their levels are identified. Suggestions to mitigate the pollution problem in urban Jordan will be considered.

\section{RESEARCH METHODOLOGY}

The used data in this research is provided by the Ministry of Environment (MOE). This data is the product of a joint undertaking made by the MOE and Public Security Department. The sample consists of 724 vehicles distributed on five age groups as shown in Table 1. The study includes the identification and the levels of pollutants emitted by all vehicles. Levels of $\mathrm{CO}, \mathrm{CO}_{2}, \mathrm{HC}$ where detected and measured. The results were compared with the local emission standards and reported accordingly. Other pollutants such as $\mathrm{SO}_{2}$, particulate matter (PM) and/or suspended particles (SP), and lead were identified. The study included records of maintenance made for some vehicles at a local service station. A basic questionnaire of 350 car owners was made. The questionnaire included information of the periods between oil changes, frequency of oil filter and air filter replacement, mileage, and age, and fuel type. The study team visited local hospitals to obtain data on emission related diseases and health risks. Very little information was collected in this regard.

Other studies conducted at the Royal Scientific Society (RSS) and the University of Jordan were reviewed. EPA and WHO standards were considered. The data provided by the MOE were analyzed; results were tabulated and then discussed. Factors affecting emission type and emission levels were studied. Some photos are also provided to substantiate study findings. Health risks associated with each pollutant are reviewed and presented.

\section{LITERATURE REVIEW}

The literature on the topic of environment and air pollution is full of examples on the potential danger of traffic pollution and its effects on global and local areas. Multistory buildings and civil infrastructures make our street as canyons. Pollutants trapped in these canyons are seen daily in our urban and suburban areas. The health risks associated with contaminated air, soils, and water are substantial.

Table 1: Tested Sample of Vehicles According to Age Groups.

\begin{tabular}{|c|c|c|c|c|}
\hline Age Group & $\begin{array}{c}\text { Regular Leaded } \\
\text { Gasoline }\end{array}$ & $\begin{array}{c}\text { Super Leaded } \\
\text { Gasoline }\end{array}$ & Diesel & Sub Total \\
\hline $0-5$ & 42 & 8 & 48 & 98 \\
\hline $6-10$ & 84 & 13 & 143 & 250 \\
\hline $11-15$ & 90 & 8 & 67 & 165 \\
\hline$>15$ & 133 & 7 & 81 & 221 \\
\hline Total & $\mathbf{3 4 9}$ & $\mathbf{3 6}$ & $\mathbf{3 3 9}$ & $\mathbf{7 2 4}$ \\
\hline
\end{tabular}




\section{The Global IsSues}

Our planet is losing three species per day [3]. If we continue to dump pollutants and toxic waste into air, water, and soil, the planet will lose more than $50 \%$ of its species in less than 50 years. Our use of inefficient cars, our trash, someone else's over use of limited resources, all make the planet less livable for the children of today and tomorrow. But remember: as much as we are the root of the problem, we are the genius engineers for its solution.

Some of the main issues of pollution affecting people at the global level are, traffic related, others are not. Vehicles are the main contributors to air pollution in many areas of the world. They produce $15-20 \mathrm{~kg}$ of pollutants for each kilograms of fuel burnt [3].

\section{The Greenhouse Effect}

Natural gases in the atmosphere form a blanket which allows sunlight to reach the earth's surface, but prevents it from escaping. However, human activities, for the first time in history, are altering the climate of our entire planet. In less than two centuries human activities increased the total amount of carbon dioxide $\left(\mathrm{CO}_{2}\right)$ in the atmosphere by $25 \%$ [2]. Every year people add 6 billion tons of $\left(\mathrm{CO}_{2}\right)$ gas which is responsible for $50 \%$ of the Greenhouse effect. Using cleaner fuel such as natural gas will cut the amount of $\mathrm{CO}_{2}$ released by half [4]. Carbon Dioxide exists in nature with $0.03 \%$ of the total gases in our air. Chlorofluorocarbons (CFCs), released from air conditioning units in old vehicles and other sources, are contributing to $20 \%$ of global warming and destroying the earth's ozone layer. Nitrogen Oxides $\left(\mathrm{NO}_{\mathrm{x}}\right)$ emitted by vehicles and fertilizers are contributing $10 \%$ of global warming. The Ozone which is caused by motor vehicles, power plants, and refineries is a contributing factor to global warming.

The greenhouse effect was responsible to the $4^{\circ} \mathrm{C}$ increase in the glob's temperature since 1900 [4]. This increase in earth temperature changes the climate and directly affects our well being.

\section{Air Pollution}

Billions of people are breathing dirty air. Over one third of world's population lives in areas where the clean air standards are exceeded. Ozone is the primary component of smog. It is a gas formed when nitrogen oxides and hydrocarbons combine in sunlight. In the atmosphere, ozone is found naturally as a thin layer that protects us from the sun's ultraviolet rays. But when it is formed at the ground surface, it is deadly. Motor vehicles are the main source of ozone. In 1986, 6.5 million tons of hydrocarbon and 8.5 million tons of nitrogen oxides were vented into the air by motor vehicles [3]. Utilities, oil and chemical plants are also a large part of the problem. The problem is catastrophic when all of these sources of pollutants are combined in one area. Lung damage from polluted air is a risk faced by 3 out of 5 people in some areas. It is one of the primary reasons for forest damage and losses of agricultural crops [5].

\section{Ozone Depletion}

The ozone layer protects and shields the earth surface against dangerous solar ultraviolet radiation. Human activities are depleting this vital and protective shield. In addition to Chlorofluorocarbons, Nitrogen Oxides, and other manmade chemicals are 
wafting up to the stratosphere, 6 to 30 miles above us. There, they break down and release atoms that destroy the ozone layer allowing ultraviolet radiation to reach the earth's surface. This radiation destroys the balance of plants and living cells, promoting skin cancer and cataracts, and depressing human immunity systems [5].

\section{Acid Rain}

Sulfur dioxide and nitrogen oxides are released by burning fossil fuel in motor vehicles and power plants. They are spewed into the atmosphere and fall back to earth as acidified rain or snow. The acidified water is destroying plants and animal life in streams. The acid rain also damages forests and erodes buildings. Sulfur dioxide $\left(\mathrm{SO}_{2}\right)$ released by diesel engines is the primary component of acid rain in many regions. Nitrogen oxides and hydrocarbons are some of the contributors to acid rain [6].

\section{Ground Water Pollution}

More than $90 \%$ of the world's supply of drinkable water is groundwater. Acid rain, contaminated surface water and soil, and land fills are some of the primary sources of underground water pollution. Gas stations' under ground tanks and pumps are leaking petroleum products into the ground resulting in water and soil contamination. In addition, residues from motor vehicle operations are pollute ground-water. One gallon of gasoline can contaminate 750,000 gallons of drinking water [7].

\section{THE JORDANIAN ISSUE}

As in many developing countries, transportation issues in private and public sectors are based on the assessment of the capital and operating costs of the transportation facilities. Explicit consideration is given to direct and indirect impacts confined to travel cost (operator travel cost and user operating cost) and land acquisition. On the other hand, the environmental movement in the developed countries resulted in an increased awareness of many indirect socioeconomic and environmental effects of transportation decisions. Air quality, noise generation, and energy consumption are some of the many transportation-related impacts that must be an integral part of contemporary transportation planning and decision making. In 1993, more than 17 million tons of pollutants were vented into the sky. About half of this amount was contributed by vehicles [4].

There are more than 600,000 vehicles in Jordan according to several studies conducted in the year 2004 [8]. This number of vehicles grew from 3426 vehicles in 1950 (Figure 1). The highway transportation sector in Jordan is by far the only transportation sector moving people and commercial goods at the local level. People are transported using the private automobile or public transportation. The private auto fleet consists of approximately half of the total number of vehicles where $50 \%$ of this number is more than 10 years of age [8]. Public transportation, however, consists of three sub- sectors. One is partly owned and run by a government agency. The second consists of taxis and what is called "service taxi" (fixed route taxis). The third is privately owned by individual or small companies. This last type consists of small buses (about 20 passengers' capacity and more). The service quality provided by this type is poor, it is unreliable and most of its users are captive users. Most of the public transport fleet, other than taxis, runs on diesel fuel. 


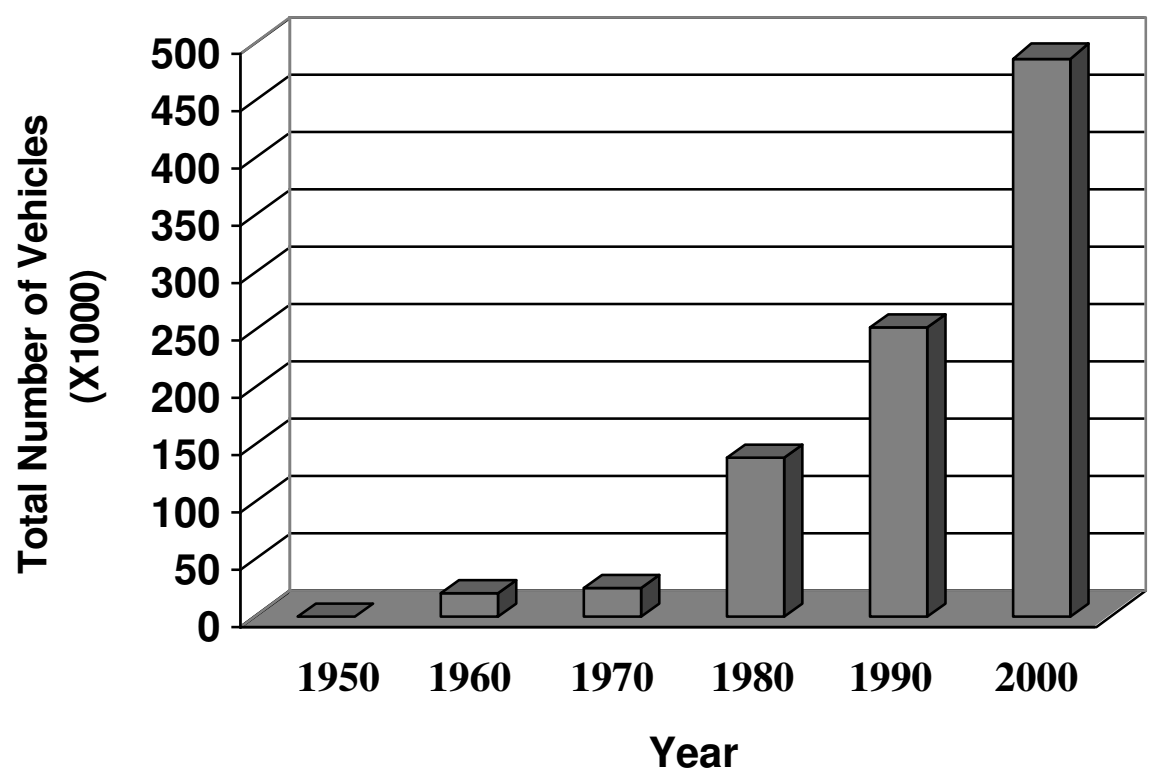

Figure 1: The Growth of Total Number of Vehicles in Jordan.

Goods are transported by medium sized to large vehicles using diesel. The traffic mix of the commercial vehicles is so diverse; it is very difficult to classify it. Gasoline operating cars amount to less than $60 \%$ of the total vehicles. On the other hand, lightto-medium diesel trucks, coaster buses and minivans make $15 \%$ of the total traffic in the Kingdom while heavy vehicles including transit buses add up to $25 \%$. The local gasoline is produced by the one oil refinery in Jordan, which itself is a major source of pollution located in Al-Zarka area. This fuel is leaded gas containing 1\% lead. The production of unleaded gasoline has just started in Jordan in 1999 where very few gas stations sell the product to less than $1 \%$ of the vehicles [8]. Most of the new gasoline cars imported to Jordan run on lead free gas. However, now the majority of those vehicles are using leaded gas. On the other hand, diesel fuel produced at the Jordan Refinery contains up to $1.5 \%$ Sulfur [4].

\section{DATA COLLECTION}

Emission data used in this study was obtained from the MOE. Data pertaining to vehicle maintenance was collected at a local service station in the suburbs of the capital Amman. Drivers' questionnaire was also made. Figures 2 and 3 show the effect of pollutants on the Capital City.

\section{EMISSION DATA}

The study consists of testing exhausts emission one day a week for a six month period. The test period started in May and ended in October, 2003. Fourteen different locations were selected within and in the out skirts of Amman. A random test sample of 724 vehicles was chosen to represent the traffic mix in urban Jordan. These vehicles were 
divided into four age groups. Two test devices were used in this process. One to measure the emission levels of $\mathrm{CO}, \mathrm{CO}_{2}$, and $\mathrm{HC}$. The other device was used to measure opacity of the diesel vehicles. The Traffic Department and Highway Patrol helped in stopping and organizing the tested vehicles.

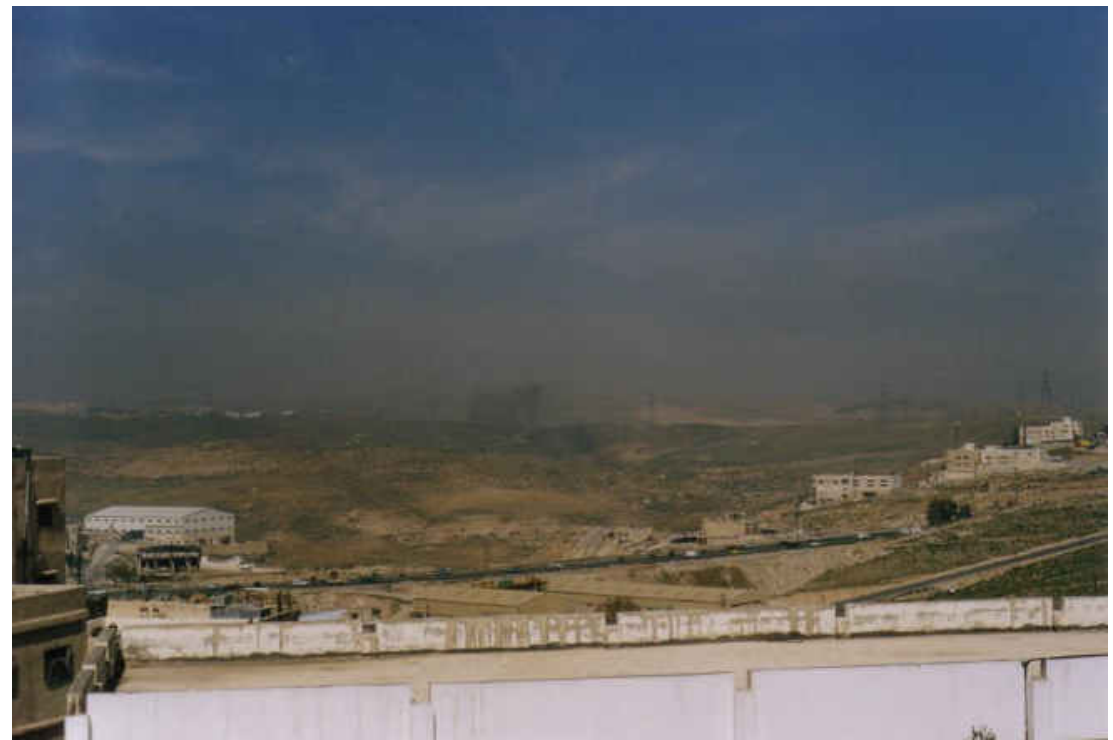

Figure 2: Clouds of Pollutants and Smog over the Skies of the Capital Amman on a Summer Day.

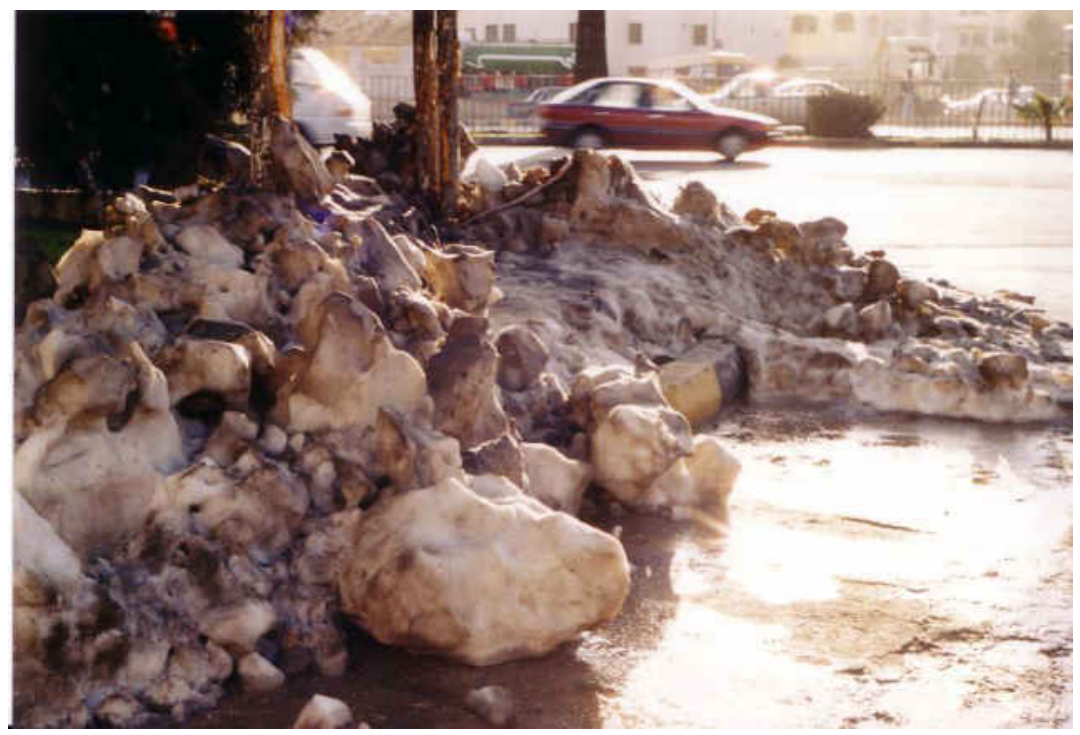

Figure 3: Pollution Covering the Snow on the Streets of The Capital City. 


\section{MaintenANCE Data}

A sample of 300 passenger cars was used for a period of four months. The maintenance data was recorded. Another sample of 50 diesel vans was also recorded. The periods between oil changes were recorded. Information related to oil filters and air filters was also obtained. The age and type of vehicles were also recorded. Figures 4, 5, and 6 show the frequencies of oil, oil filter, and air filter replacement for the sample of vehicles with respect to their age groups.

It is clear that the proper maintenance is not maintained as required to keep the rate of pollutants down.

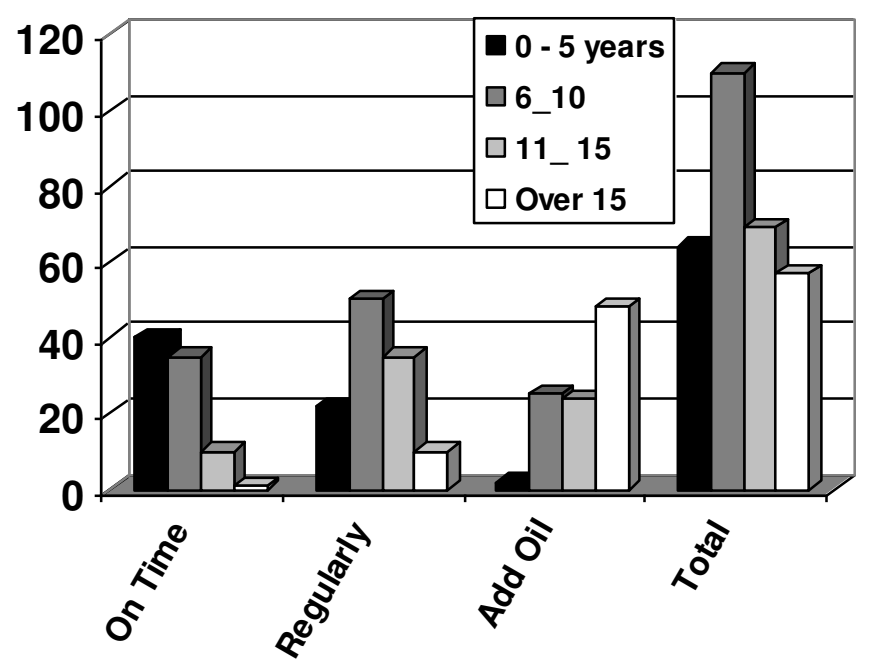

Figure 4: The Frequency of Oil Change as Reported by the Drivers in the Questionnaire.

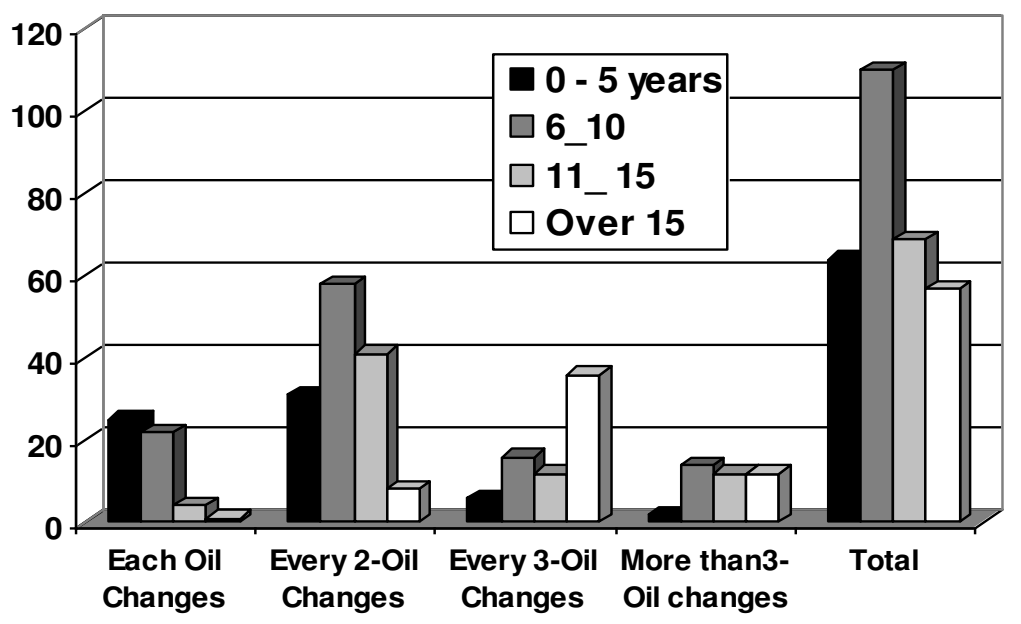

Figure 5: The Frequency of Oil Filter Change as Reported by the Drivers in the Questionnaire. 


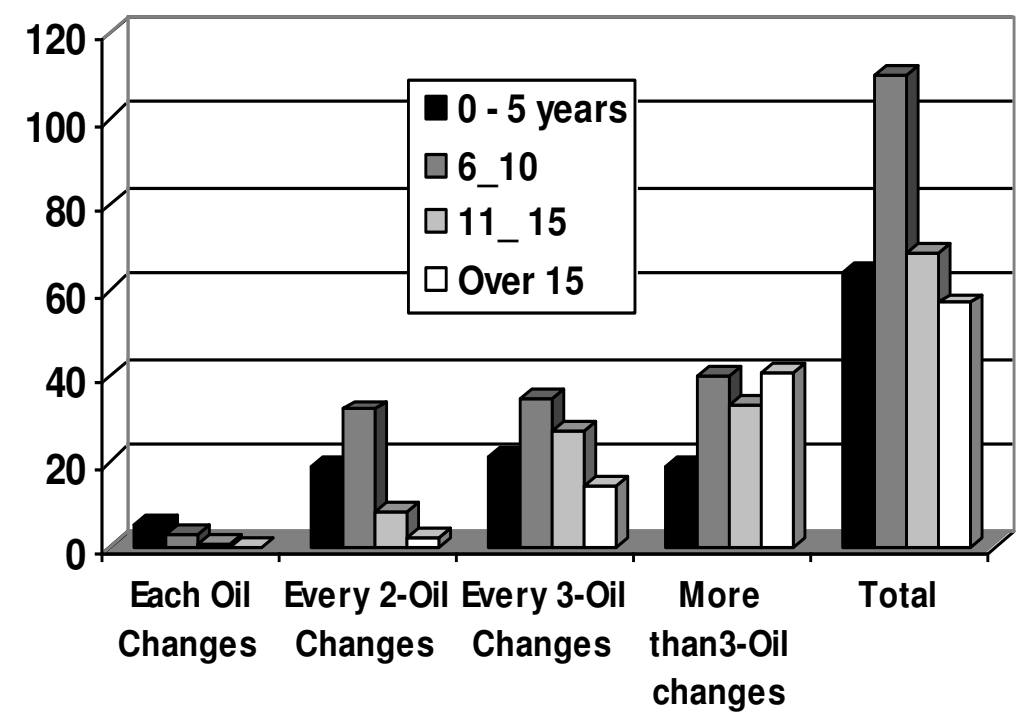

Figure 6: The Frequency of Air Filter Change as Reported by the Drivers in the Questionnaire.

\section{DISCUSSION OF RESULTS}

For the past five years the capital city has almost been covered with smog on windless days. This is evident to anyone looking at the capital from the surrounding area. The capital city's streets are polluted with smoke most of the time. In general, more than $58 \%$ of the tested vehicles exceeded the allowable levels of pollution according to local standards. The violation rate differs according to age groups and type of the used fuel. Table 2 shows the number of vehicles exceeding the allowable emission pollutants level with respect to age groups and type of fuel used.

Table 2: The Ratio of Vehicles Exceeding the Allowable Emission Pollutants Levels According to Age Group and Fuel Type.

\begin{tabular}{|c|c|c|c|c|}
\hline Age Group & $\begin{array}{c}\text { Regular Leaded } \\
\text { Gasoline }\end{array}$ & $\begin{array}{c}\text { Super Leaded } \\
\text { Gasoline }\end{array}$ & Diesel & Sub Total \\
\hline $0-5$ & $30 / 42$ & $5 / 8$ & $24 / 48$ & $59 / 98$ \\
\hline $6-10$ & $37 / 84$ & $4 / 13$ & $80 / 143$ & $121 / 250$ \\
\hline $11-15$ & $65 / 90$ & $5 / 8$ & $43 / 67$ & $113 / 165$ \\
\hline$>15$ & $75 / 133$ & $6 / 7$ & $47 / 81$ & $128 / 221$ \\
\hline Total & $207 / 349$ & $16 / 36$ & $194 / 339$ & $\mathbf{4 1 7 / 7 2 4}$ \\
\hline
\end{tabular}

\section{Diesel VehicLes}

More than $57 \%$ of the tested diesel vehicles exceeded the allowable local emission limits. Figure 7 shows the rate of diesel tested vehicles according to the age groups. About $50 \%$ of the total vehicles aged less than five years exceeded the limits of 
allowed emission. More than $56 \%$ of the vehicles aged between six to ten years were in violation with the emission standards. The age group 11 to 15 years showed more than $64 \%$ of total vehicles in violation. The percent of vehicles violating the emission regulation is $58 \%$ for the group older than 15 years. This trend shows an increase in emission violation as the age of vehicles increase. The last group, however, has less violation rate. This is explained by the fact that most diesel vehicles above 15 years of age undergo an overhaul to their engine.

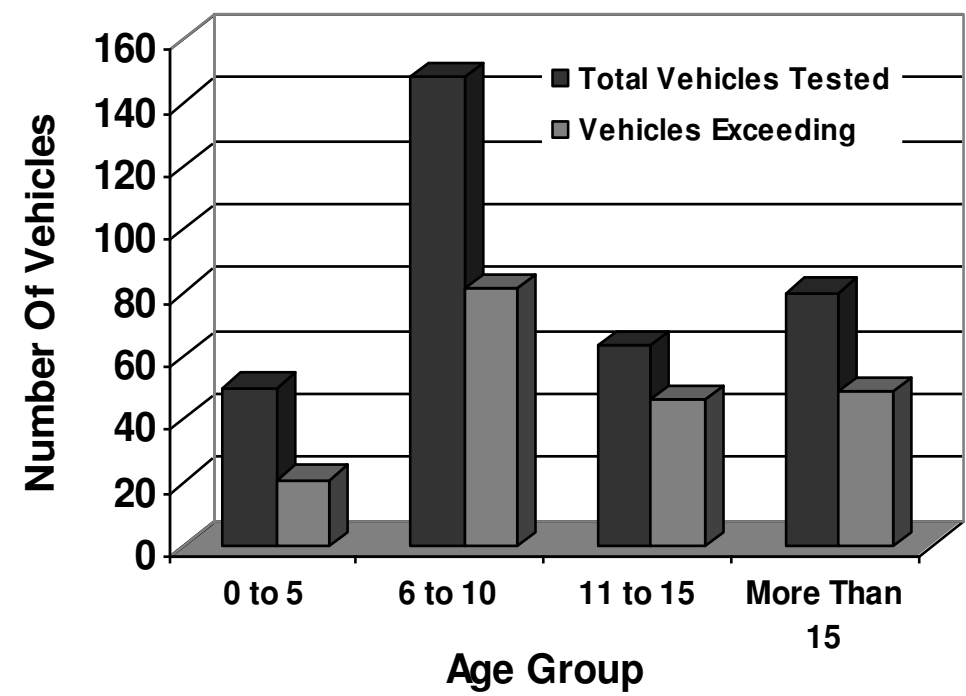

Figure 7: Number of Diesel Vehicles Exceeding the Emission Pollutants Limits According to their Age Group.

\section{GASOLINE VEHICLES}

The tested gasoline vehicles are divided into two subgroups, one runs on unleaded and the other run on leaded fuel. The group running on unleaded fuel showed higher compliance rate at early age (less than 10 years). The rate of compliance with emission limits declines rapidly after ten years of age (see table 2). More vehicles running on unleaded gas need to be tested in order to generalize this assumption.

Leaded (regular) fueled vehicles less than six years of age showed $75 \%$ percent of violation. This is the highest rate of all. The study suggests that most cars with an age of six years or less specify the use of unleaded and were converted to regular leaded gasoline due to the high price and the lack of this product in Jordan. Cars of ages between six and 10 years are the lowest rate in exceeding the emission limits (see Figure 8). Only $39 \%$ of these vehicles were in violation of the standards. The next age group, however, showed violation rates of more than $72 \%$. This is due to a lack of maintenance where most car operators kept the same air filters and oil filters on their cars for a period equal to double and triple that specified. Vehicles more than 15 years showed violation rates less than the previous group. This rate is decreased to $56 \%$ due to the fact that most vehicles within this age group have rebuilt engines. 


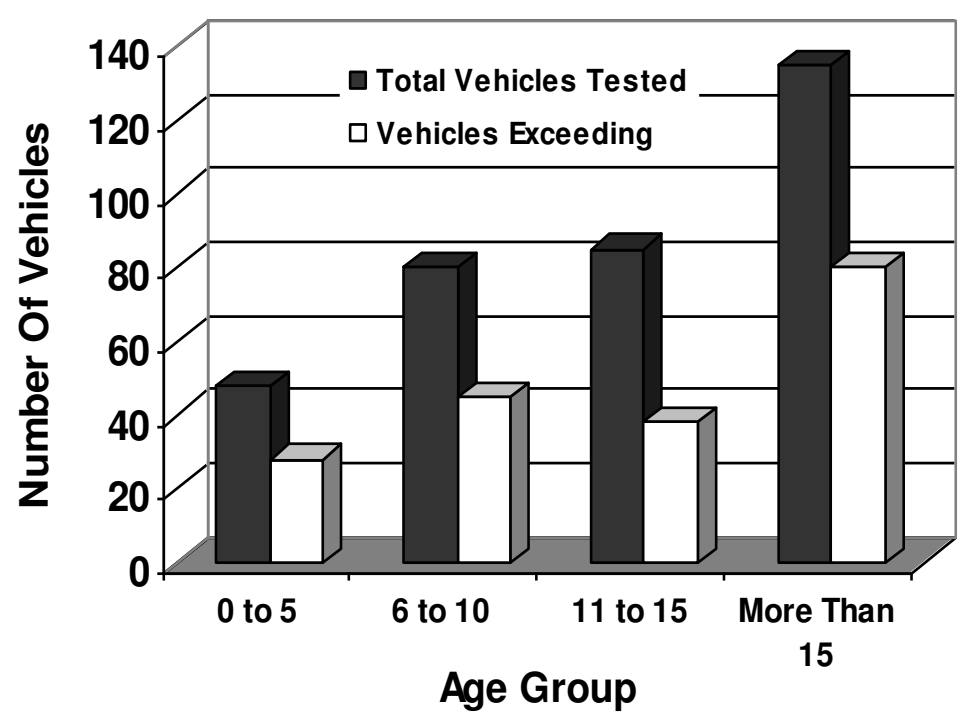

Figure 8:Gasoline Vehicles Exceeding the Emission Pollutants Levels According to their Age Groups.

\section{FACTORS AFFECTING EMISSION LEVEL AND COMPOSITION}

The level and composition of exhaust fumes depends on many factors. The following subsections are some of these factors affecting the levels of emission in urban Jordan.

\section{QUALITY AND PRICING OF FUEL}

The transportation sector in Jordan uses diesel and gasoline. Diesel fuel is relatively cheap in comparison with gasoline prices. This is the main reason behind the high number of diesel vehicles in the Jordanian traffic stream. The price of diesel is less than one third of the price of gasoline. The quality of Jordanian diesel fuel is very low with $1.5 \%$ sulfur content. Sulfur damages the emission control devices in most diesel vehicle at early age and increases the pollution level in the capital city.

Gasoline fuel in Jordan contains about $1 \%$ lead. Most developed countries are using lead-free gas. Unleaded is sold at a very few gasoline stations in Amman with a price equivalent to 1.5 times that of leaded gas. Therefore, people change their new cars from unleaded to leaded gas. The conversion process will not only increases lead in air, but damage the emission regulatory devices in the new vehicle contributing to more exhaust pollutants [9].

\section{ENGINE TYPE AND VEHICLE SPECIFICATION}

The study showed that engine type and specifications affect the rate of pollutant released by different vehicles. The rate of compliance with emission limits declines rapidly after ten years of age (see table 2). More vehicles running on unleaded gas 
need to be tested in order to generalize this assumption. Leaded (regular) fueled vehicles less than six years of age showed $75 \%$ percent of violation, which is the highest rate.

\section{CONCLUSIONS AND RECOMMENDATIONS}

\section{CONCLUSIONS}

From the above study, the following conclusions can be drawn:

1. More than $80 \%$ of the total vehicles in Jordan are registered in the Amman/AlZarqa area. About half of the vehicles are more than 10 years old.

2. $60 \%$ of vehicles use gasoline, while the rest use diesel with more than $1.5 \%$ sulfur content.

3. The used gasoline in Jordan is a regular leaded gas with $1 \%$ lead. Unleaded gas is used by less than $1 \%$ of vehicles.

4. The tested sample in this study included 349 vehicles used regular leaded gasoline, 36 vehicles used super leaded gasoline, while 339 of the sample ran on diesel fuel.

5. $60 \%$ of the gasoline fueled vehicles sample exceeded the allowable Jordanian standard for emission, while $57 \%$ of the diesel vehicles were in violation of these standards.

6. It is found that there is a lack of proper maintenance to most vehicles. This adds to the amount and severity of pollutants released by those vehicles.

7. Scheduled reliable mass transit systems should be considered for Jordan to reduce the amount of traffic pollution.

8. Pollution control devices should be mandatory and regular inspection as well as regular vehicle maintenance are required.

\section{RECOMMENDATIONS}

The study suggested the following recommendations:

1. Vehicles should be tested for other pollutants.

2. More scientific investigation should be carried out including more vehicles.

3. The use of leaded gasoline should be replaced by lead free gasoline. More gas station should provide this type of gasoline.

4. People should be encouraged to use pollution reduction devices.

\section{REFERENCES}

[1] Perkins, H.C.A: Pollution, McGraw-Hill, New York, 1974.

[2] Lee C.E, and Lee F.P, Simulation of Traffic Performance, Vehicle Emissions and Fuel consumptions at intersection, NY, 1998.

[3] Alliance of Automobile Manufactures Docket No. A - 99- 06, Washington, DC., USA, 1999.

[4] Jordanian Journal of Energy, V. 8, No. 3, National Energy Research Center, Amman, Jordan, Sept., 2004.

[5] John Hart, B.A "Saving Cities Saving Money": Environmental Strategies That Work, 2004. 
[6] Acid Rain, The EPA Acid Rain Program 2004, Progress Report, Washington DC., USA, 2004.

[7] Fifty Simple Ways to Save the Earth, Earthworks Group, McMeel, Washington, DC., USA, 1990.

[8] Jordanian Directional Licenses Department Report, Amman, Jordan, 2003.

[9] Energy Conservation and Emission Reduction Strategies, Victoria Transport Policy Institute, Victoria, BC, Canada, 2005.

\section{التلوث الناتج عن حركة المرور بالمناطق الحضرية في الأردن}

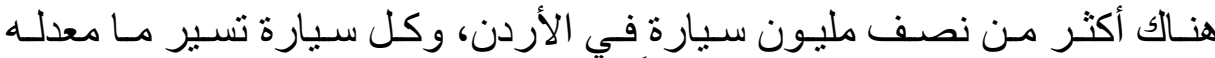

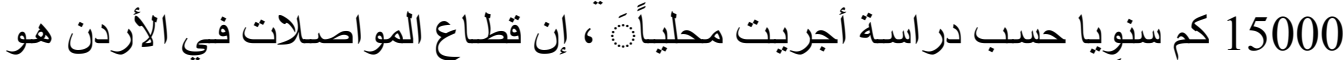

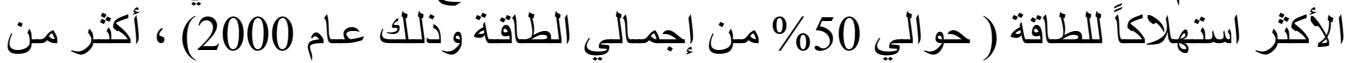

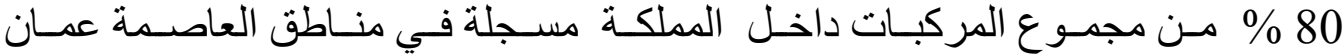

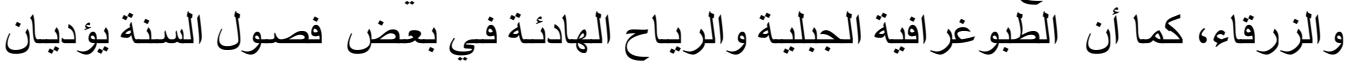
إلى تركيز عالٍ في الانبعاث الذي يصدر عن هذه المركبات في هاتين المدينتين .

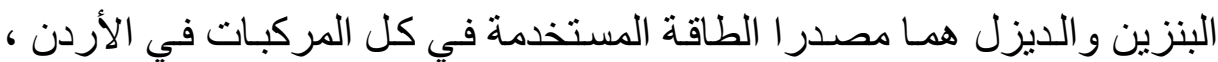

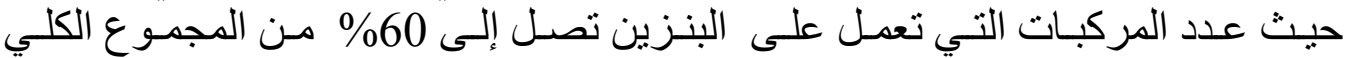

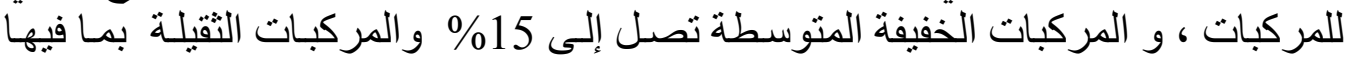

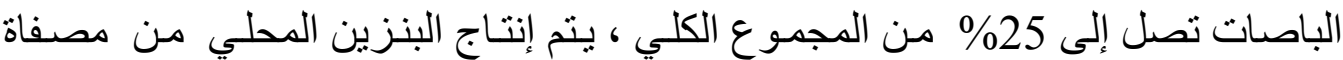

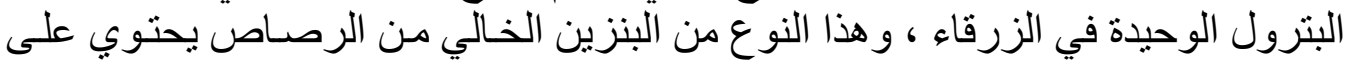

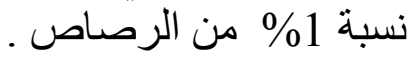

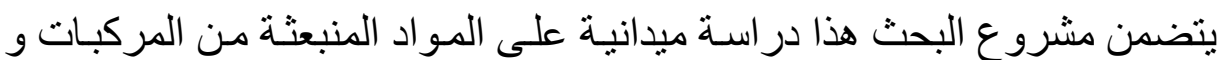

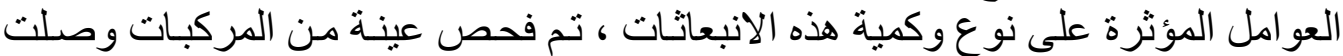

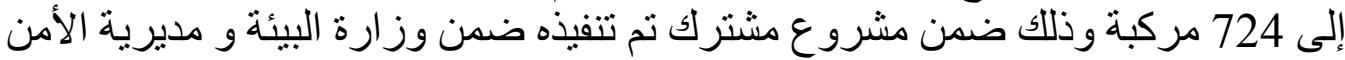

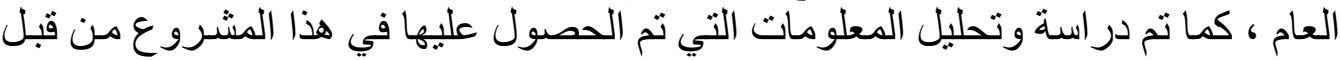
باحثين في كلية الهندسة التكنولوجية دانية - جامعة البلقاء التطبيقية.

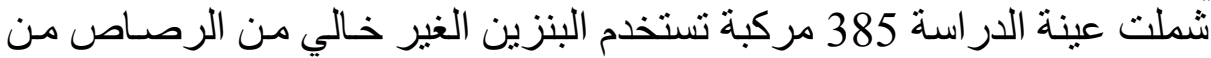

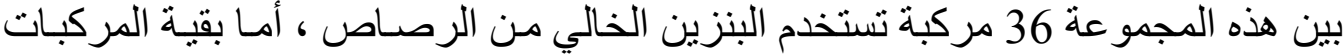

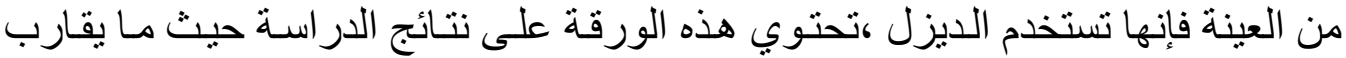

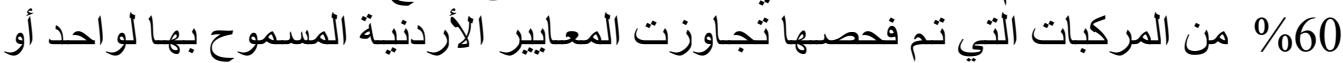
أكثر من الملوثات ، ومن الناحية الأخرى كان هناك أكثر من 57 \%

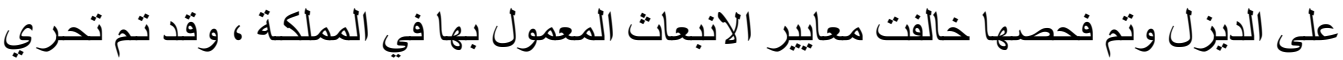

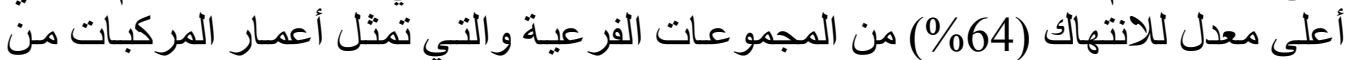

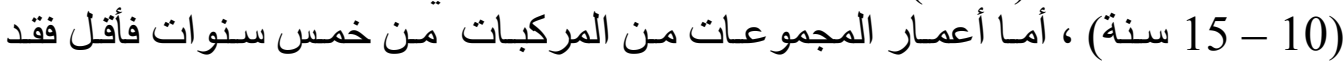




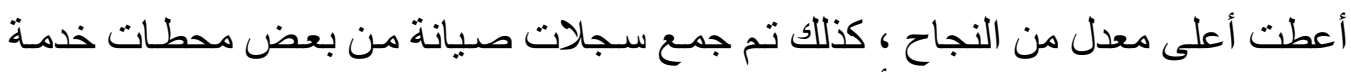

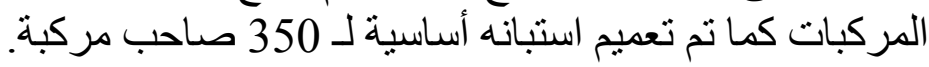

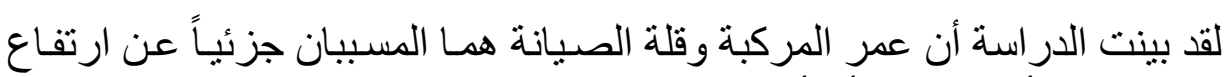

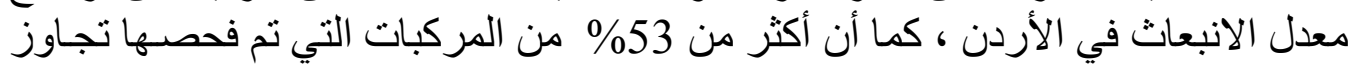

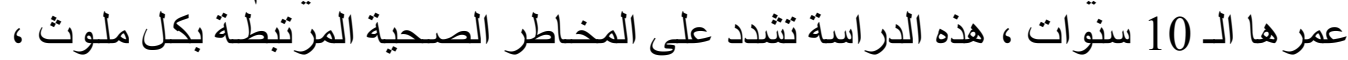

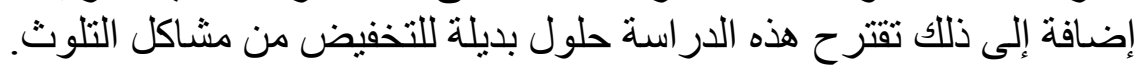

